\title{
Positive PSychology AND THE TRAining OF PSYCHOLOGISTS: STUDENTS' PERSPECTIVES
}

Author:

Tharina Guse

Affiliation:

${ }^{1}$ Department of Psychology, University of Johannesburg, South Africa

Correspondence to: Tharina Guse

email:

tguse@uj.ac.za

\section{Postal address:}

Department of Psychology, University of Johannesburg PO Box 524, Auckland Park 2006, South Africa

Keywords:

psychofortology; psychological well-being; professional training; psychotherapy; qualitative research

Dates:

Received: 06 Aug. 2009 Accepted: 14 Sept. 2009 Published: 03 Dec. 2010

How to cite this article: Guse, T. (2010). Positive psychology and the training of psychologists: Students' perspectives. SA Journal of Industrial Psychology/SA Tydskrif vir Bedryfsielkunde, 36(2), Art. \#848, 6 pages, DOI 10.4102/sajip.v36i2.848

This article is available at: http://www.sajip.co.za

(C) 2010. The Authors. Licensee: OpenJournals Publishing. This work is licensed under the Creative Commons Attribution License.

\section{ABSTRACT}

Orientation: The development of positive psychology interventions have burgeoned internationally and are relevant to the professional training of psychologists

Research purpose: The aim of this study was to explore the personal and professional impact of including positive psychology in the professional training of clinical and counselling psychologists.

Motivation for the study: It is not known how students previously educated in a pathogenic paradigm experience the exposure to positive psychology, and resultant paradigm shift, as part of their professional training

Research design, approach and method: A qualitative research design was implemented. Data consisted of written documents submitted by the participants and was analyzed by means of thematic analysis.

Main findings: Integrating positive psychology in the professional training curriculum was valuable and enriching on both a professional and personal level. The participants reported an experience of positive emotions and increased sense of self-understanding and psychological wellbeing. Professionally they experienced a sense of increased self-efficacy.

Practical/managerial implications: Positive psychology should be considered as part of the basic training of psychologists since it may enhance the development of trainee psychologists' professional self, enhance aspects of psychological well-being as well as prevent stress and burnout.

Contribution/value-add: This is the first South African study to explore the impact of including positive psychology principles and interventions in professional training.

\section{INTRODUCTION}

The movement towards acknowledging, understanding and enhancing the positive aspects of psychological functioning has gained tremendous momentum in the past decade. This field of enquiry, described as positive psychology (Seligman \& Csikszentmihalyi, 2000) or psychofortology (Wissing \& Van Eeden, 2002), has yielded much research on construct clarification, the manifestation of positive psychological functioning and the measurement thereof. Recently, there has also been increased focus on the application of positive psychology principles in professional practice (Rashid, 2009). By implication, positive psychology interventions should also be incorporated into the professional training of psychologists. How is this paradigmatic shift experienced by trainee psychologists who have been exposed mostly to a pathogenic approach in both undergraduate studies and professional training? This article attempts to shed light on this question and discuss the implications thereof for the training of clinical and counselling psychologists in the South African context.

Positive psychology developed largely in reaction to the disease model prevalent in contemporary psychology (Seligman, Steen, Park \& Peterson, 2005). It has been defined as the scientific study of what makes life most worth living (Seligman \& Csikszentmihalyi, 2000) as well as of optimal functioning (Linley, Joseph, Harrington \& Wood, 2006). From this perspective, however, the study of diseases, disorders and abnormalities, although important, ignores other more positive aspects of life, such as subjective well-being (Diener, 2000), positive affect and human flourishing (Frederickson, 2001, 2002; Keyes, 2007), and character strengths and virtues (Peterson \& Seligman, 2004).

Although Martin Seligman is widely credited for coining the term 'positive psychology' and instigating scientific enquiry into the field, views on positive psychological functioning have existed since at least the beginning on the 20th century. Strümpfer (2005) provided an extensive overview of the predecessors of positive psychology, such as William James, Carl Jung and Abraham Maslow. He further suggested that the term 'psychofortology', as formulated by Wissing and Van Eeden (2002), be seen as an alternative for positive psychology. According to Wissing and Van Eeden, psychofortology refers to a new subdiscipline in psychology that focuses on ways to enhance psychological well-being and develop human capacity. Wissing and Van Eeden's designation is derived from Strümpfer's (1995) term 'fortology', which refers to the study of strengths. If positive psychology is seen as the study of psychological strengths (psychofortology), it therefore means that the identification of these strengths and their application in the context of psychotherapy and counselling are important aspects to be considered in the professional training of psychologists.

Another issue to consider when positive psychology is included in professional training involves the resulting paradigmatic shift in how counselling and psychotherapy are viewed. Focusing on strengths and positive psychological functioning is often described as a different paradigm within psychology, 
as opposed to the long-standing pathogenic paradigm. The pathogenic paradigm focuses more on the detection of deficits, with the role of psychologists being to assess and treat individual suffering (Strümpfer, 2005). Since the field of positive psychology is relatively new, most postgraduate students were exposed to the pathogenic paradigm in their undergraduate training. It is therefore possible that students have developed a specific lens through which they view psychology and psychotherapy. It is not yet known if and how students are able to accommodate the alternative paradigm, nor how it could impact on their training as psychologists.

The development and evaluation of psychological interventions from a positive psychological perspective have received increased attention in the last five years. For example, Seligman et al. (2005) have reported on the effect of an intervention to increase happiness and decrease depressive symptoms, while Smith (2006) has proposed a strengths-based model for counselling at-risk youth. Joseph and Linley (2006) have argued that a positive psychological perspective is relevant in all therapeutic contexts and that the role of psychologists should go beyond alleviating distress to facilitating wellbeing and fulfilment, as this could serve as a buffer against the development of psychopathology. In addition, a special issue of the Journal of Clinical Psychology (Vol. 65, No. 5, 2009) was recently devoted to positive interventions. Positive psychology principles are thus increasingly being incorporated into the practice of psychotherapy. Therefore, this perspective should be considered in the training and education of psychologists. However, although South African researchers are actively investigating the effectiveness of interventions that could facilitate wellness (Viviers \& Coetzee, 2007), the implementation of positive psychology principles and strategies in professional education and training is still limited to only a few training programmes in South Africa.

Given the increased use of positive therapeutic interventions and the impetus towards the scientific evaluation of this approach, the research question of this study is: How do trainee psychologists in a master's course in clinical and counselling psychology experience the introduction of positive psychology as a therapeutic modality in professional training? In the light of increased pressure for master's degrees to be completed within a specific timeframe, limited teaching resources and the unique needs of the South African context regarding psychological services, answering this question could therefore shed light on the possible role of positive psychology in professional training.

To answer the research question, three specific aims were conceptualised

- To explore students' reflections of their experience of being introduced to positive psychology.

- To explore students' perceptions of applying positive psychology in a therapeutic context.

- To explore students' experience of identifying their own psychological strengths in the context of training.

\section{RESEARCH DESIGN}

\section{Research approach}

This research was qualitative and exploratory. Qualitative research is often employed when the aim is to explore a topic that is new or has not yet been addressed with a certain group (Creswell, 2003). This approach was therefore considered relevant for this study, since the aim was to explore and understand students' experiences as described by them. Within the broad qualitative tradition, several qualitative approaches exist, often seen as very diverse, complex and nuanced (Holloway \& Todres, 2003). For this study, thematic analysis, considered by Braun and Clarke (2006) as a qualitative method in its own right, was adopted to identify, analyse and report patterns within data. The thematic analysis was applied from an essentialist or realist paradigm, with the aim of reporting experiences, meanings and the reality of participants (Braun \& Clarke, 2006)

\section{Research method \\ Participants}

The participants in the study were purposefully selected (Creswell, 2003), as they were the ones who could best assist the researcher in addressing the research problem. All the students who were in their first year of the MA (Psych) degree in the Department of Psychology at a Gauteng university participated voluntarily in the study. This degree would lead to registration as either a clinical or a counselling psychologist, with no differentiation in course content. There were four male participants and six female participants, their ages ranging from 22 to 43. Eight of the participants were White, one was Black and one was Indian. The researcher was the lecturer responsible for presenting the workshop on positive psychology as well as being the coordinator of professional training.

\section{Data gathering and analysis}

The data consisted of written accounts submitted by the participants. In these documents, they reflected on their experience of being introduced to a 20-hour workshop on positive psychology as part of the core curriculum in the training programme. According to Creswell (2003), documents often present data that are thoughtful, since participants could have given considerable attention to their compilation.

The following was requested of the participants:

Reflect on the impact, if any, of the workshop on yourself, also in terms of your awareness of your particular psychological strengths. Further, reflect on the possibilities of integrating Positive Psychology principles and techniques into your evolving understanding of human problems and your approach to therapy.

Written consent to use these documents was obtained from the students before this research was embarked on. The documents were analysed by means of thematic analysis (Braun \& Clarke, 2006). This included familiarisation with the data in order to search for meanings and patterns, while also attempting to bracket own assumptions to allow further themes to emerge. This was followed by the generation of initial codes, leading to the formulation and definition of themes and sub-themes.

Due to the subjective nature of this research, it was important to ensure research quality and to lessen possible bias. To increase the validity of the research findings, the following strategies were therefore implemented: Firstly, the researcher was aware of her own bias as presenter of the workshop and coordinator of professional training. To address this issue, she attempted to bracket her own assumptions. Secondly, two separate analyses were conducted, with four months between the analyses. According to Krefting (1991), this strategy adds to the dependability of results. Finally, peer debriefing (Creswell, 2003) was used to review the study and enhance the accuracy of the account.

Due to the exploratory nature of this study, the intention was not to generalise findings but to formulate hypotheses for further empirical research.

\section{FINDINGS}

Seven main themes and related sub-themes were found in the participants' descriptions of their experience. These themes were clustered around the research aims, as previously explained. The themes will be discussed in conjunction with direct quotes and will also be contextualised within existing literature.

\section{Participants' experience of being introduced to positive psychology}

Theme 1: Varied initial reactions

The trainees' accounts reflected that they were aware of 
specific initial reactions once introduced to the topic of the workshop. Three sub-themes were identified that can be referred to as apprehension, scepticism and reawakening. Most of the students recounted initial apprehension and scepticism towards positive psychology. One student eloquently referred to her previous experiences with 'positive thinking' and workshops for young people to 'find themselves'. Having worked for a company that presented such workshops, she remarked as follows: 'I felt cheated and disillusioned with what I experienced as a false dream.'

Some of the students assumed that the study of positive psychology implied an 'either/or' approach, seemingly incompatible with studying psychopathology and being a psychologist. One student remarked as follows: 'Is life not supposed to be a struggle?'

Therefore, for the majority of the students, the idea of focusing on positive emotions, constructs and interventions was met with apprehension and uncertainty about relevance to the practice of psychology. This initial reaction could be explained by psychology's long-standing focus on pathology in understanding and treating psychological problems (Ingram, 2005; Strümpfer, 2005; Tilson, 2006), which could imply that studying more positive aspects is not relevant to clinical practice. It also points to a lingering effect of the pathogenic focus in undergraduate training that extends to professional training.

However, for a few of the students, the introduction of positive psychology was a reawakening and affirmation of their existing world-view and interest in optimal functioning. These students mentioned how they were initially interested in studying psychology after observing how someone overcame adversity. Therefore, they wanted to understand more about these aspects that allowed individuals to cope and to thrive. One student remarked as follows:

... it felt more like an experience of remembering . . as though I was becoming aware of something I already knew. Interestingly, although it was something I practised in my own life, it was not something that I included in my therapy. Up until this point I had been trained to look for symptoms and psychopathology. Although I saw strength in all of my clients I had not formally identified their strengths as I had identified their weaknesses.

(Respondents)

This student's perspective reflects Ingram's (2005) contention that therapists often implicitly incorporate principles of positive psychology into psychotherapy. Yet, for these students, it was not explicitly addressed in their study of psychology and perhaps receded into the background due to pathogenic focus in their education.

\section{Theme 2: Impact of pathogenic bias in psychology on professional training}

All the students commented on their awareness of the pathological bias in psychology and, specifically, in their education and training in psychology. Some of the students mentioned being overwhelmed by this focus, as reflected by the following remark: 'I loved it at times and at other times felt simply overwhelmed when it appeared that pathology was central to psychology as a profession.'

Three decades ago, Strümpfer (1979) expressed concern about the emphasis on psychopathology in the training of psychologists. Snyder and McCullough (2000) later described how the bias towards psychopathology has shaped the thinking of young academics, resulting in the continuation of focus on the negative side of human existence. Similarly, Snyder and Elliot (2005) noted that curricula overwhelmingly seemed to align research and teaching towards individual weaknesses.
This trend was also reflected in the participants' education in psychology.

Some of the students mentioned that the focus on pathology distracted them from their initial interest in strengths and optimal functioning. Therefore, they were more inclined to diagnose weakness rather than to identify capacity. It also made them question the effect of psychotherapy, as reflected in the following statements:

Up until this point I had been trained to look for symptoms and psychopathology. Although I saw strength in all of my clients I had not formally identified their strengths as I had identified their 'weaknesses'.

As this is what we are taught for many years, it is easy after a while to become disillusioned by what psychology and the psychologist can actually do for the patient or client that is in need.

(Respondents)

Lopez, Snyder and Rasmussen (2003) have argued that professional training influences the basic features of practising psychology, such as determining which aspects of clients' lives should be focused on. For these students, the pathogenic bias of education and training in psychology seemed to be overwhelming, distracting and disempowering, resulting in a limited and possibly disenchanted view of clients and psychotherapy.

\section{Theme 3: Experienced positive personal impact}

Reflecting on their introduction to positive psychology, all the students stated that they experienced a positive personal impact. Some of the students' responses suggested that they experienced positive emotions and felt empowered:

Comparing my mood during the workshop with my mood in other courses this year I must say that there was a marked increase in my feeling good.

It speaks to me of my own possibilities.

(Respondents)

Other students mentioned that they experienced a sense of personal growth and foresaw a lasting impact on their lives, as reflected in the following comment:

I had changed from pursuing happiness to pursuing purpose in life. It seemed so complicated at times. Now, however, I have a clearer roadmap to follow; I am focusing on my progress with regard to meaning and purpose.

(Respondents)

Much has been written about the personal effect of training as a psychotherapist and, more specifically, about the negative aspects (Kottler \& Swartz, 2004; Truell, 2001). However, almost two decades ago, Blocher (1987) already argued that the extent to which training programmes were growth-promoting was a critical aspect of professional training. For the students in this study, the inclusion of positive psychology seemed to contribute to experiencing more positive emotions and, possibly, personal growth in their training. According to Frederickson's (2001) broaden-and-build theory, positive emotions contribute to the building of personal resources. Therefore, these positive emotions and experiences could serve as a buffer against possible negative effects associated with the profession, as will be discussed later.

The students furthermore became aware of the current negative aspects of their training. Specifically, many remarked that they experienced an imbalance in their lives, with an overemphasis on intellectual pursuits and less time to focus on other activities. One student reported as follows:

.. meeting the requirements of the programme on an ongoing basis is an all consuming process. Setting aside the needs of other aspects of one's life starts off as an exception and progresses to becoming the norm. By the time I was just a few months into the course I found my life completely unbalanced in favour of 
the Masters [sic] programme. This lack of balance has certainly impacted on my well-being.

(Respondents)

This sense of imbalance in the training of psychologists has previously been highlighted by Bacon (2005). He has noted that students are often required to give central position to their training, to make sacrifices and to put their lives on hold. This is regularly seen as the expected rites of passage into the discipline. Such an approach could prevent students from attaining a good life, making it something reserved only for clients (Mollen, Ethington \& Ridley, 2006).

Therapists failing to satisfy their own needs while exceeding their own capacities could lead to stress and burnout (Halewood \& Tribe, 2003). Recent research has suggested that South African psychologists seem unable to manage their own emotional distress, as manifested in symptoms of depression and anxiety (Jordaan, Spangenberg, Watson \& Fouchè, 2007). It is possible that the imbalance already created by the nature of professional training contributes partially to a continued source of stress in psychologists' lives. Jordaan et al. (2007) have suggested that psychologists be encouraged to nurture their own psychological well-being and that this should start during initial training. For some of the students in this study, an introduction to positive psychology made them aware of the possible negative impact of the profession and the importance of nurturing personal well-being. Therefore, including a positive psychology approach in professional training could contribute to facilitating the psychological well-being of future psychologists.

\section{Theme 4: Positive effect on group dynamics and sense of community}

Professional training takes place mainly in group context. For this group, the positive psychology workshop seemed to create an awareness of each person's strengths and positive attributes, which, in turn, contributed to group cohesion, as reflected in several students' accounts. One student remarked as follows:

Although some of our similar strengths, such as spirituality, humour and industry, draw us together, the fact that we have different strengths helps us too. We complement one another.

Positive psychology research has found that other people matter (Peterson, Park \& Sweeney 2008) and that group wellbeing is important for individual well-being. Therefore, a positive group experience in professional training, as elicited by a positive psychology stance, could be conducive to students' well-being. Kottler and Swartz (2004) have described the class as a community where students are supported in developing their professional identity. In this sense, it seemed that a focus on positive psychological constructs has contributed to the experience of a positive sense of community and has thereby enhanced the development of the professional identity of these students.

\section{Applying positive psychology in a therapeutic context}

Theme 5: Acknowledging strengths is empowering for both therapist and client

An important theme that emerged was that a positive psychology perspective was empowering for the psychologists in training, as reflected by the following statements:

It increased my awareness of where I am in life and the possibilities for the future. I believe that it will increase my effectiveness as a therapist.

After developing a holistic understanding of $M^{\prime}$ s [the client] strengths and challenges, I found the therapy to be more meaning ful and had more flow.

(Respondents)
Most of the students reflected on how strategies that identified and worked with clients' psychological strengths made an immediate empowering impact on their clients and, in turn gave them, as therapists, a sense of accomplishment. One student described therapy with a client as follows:

By the end of our sessions... she seemed to be far more empowered .. she began to report all the changes and plans she had made in her own time.

(Respondent)

This could reflect an increased sense of self-efficacy experienced by the participants. Such an experience could also enhance the psychological well-being of student psychologists at a time when their resources are tested to the full. Howard (2008, p. 108) has described self-efficacy as 'one's judgment of one's ability to carry out required tasks, actions or roles'. For these students, applying positive psychology principles seemed to enhance this judgment of their professional ability.

However, one student mentioned that she initially struggled to incorporate a positive psychology approach into therapy, fearing that it could be disrespectful to the client. She said the following: 'I sometimes found it disrespectful to focus on the strengths of a severely pathological patient when there is so much apparent suffering and pain.'

Psychologists often have to deal with the harsh realties of clients emotional pain (Ingram, 2005). Therefore, training in applied positive psychology has to be implemented sensitively and thoughtfully to ensure that students implement interventions appropriately.

\section{Theme 6: Awareness of relevance in the South African context}

Several of the participants referred to the importance of incorporating positive psychology into professional education and training to address the unique needs of the South African context. Due to the continuing disparities in health-care standards of living, however, it is often easier to focus on the negative aspects that exist in society. Yet, as one student remarked, approaching clients with a focus on strengths could provide, at the very least, positive emotional experiences. Since research has suggested that the experience of positive emotions could build resources and enhance psychological well-being (Fredrickson 2002; Fredrickson \& Joiner, 2002), these small changes could lead to bigger changes, which are desperately needed in South African society. The student remarked as follows:

During this year I had become frustrated with the world. I became upset that society allowed the atrocities that I was seeing to exist. Added to this the extreme poverty I was faced with made me feel powerless. This powerless, frustrated and desperate feeling affected my therapy, and the therapy affected my feelings... After I began to take a positive psychology stance my experiences seemed to change ... and I felt that these ladies [the clients] left the session, with, at the very least a positive experience.

(Respondent)

Snyder, Ritchel, Rand and Berg (2006) have pointed out that traditional pathological emphasis could also influence how clients view themselves, namely being more aware of their weaknesses and less aware of options and coping strategies. Instead, empowering clients who are in dire socio-economic circumstances by increasing positive emotions and identifying psychological strengths, such as hope, kindness, gratitude and forgiveness, to name a few, could contribute to transforming society as a whole. Indeed, Ahmed and Pillay (2004) strongly argued for a re-examination and re-formulation of the teaching of clinical psychology in South Africa to make it more relevant in the current social, political and economic context. Including positive psychology interventions, constructs and principles in professional education and training could also contribute through a focus on strengths, empowerment and the building of psychological resources. 


\section{Participants' experience of identifying their psychological strengths}

Theme 7: Identifying personal psychological strengths is empowering and affirming in the professional training context

Following Lopez et al.'s (2006) suggestion of developing a 'strengths vocabulary' that could be used in the practice of psychotherapy, students were requested to complete the Valuesin-Action Inventory of Strengths (Peterson, Park \& Seligman, 2005) online. Completing this questionnaire enables individuals to identify their signature strengths. For the purposes of this study, the reliability and validity of the questionnaire were not considered relevant, since focus was on the utilisation of the information within the training context rather than on the making of generalisations about the students' strengths.

Identifying their psychological strengths had a strong impact on all the students. They reported that being aware of and applying their signature strengths gave an experience of 'functioning better', being 'more satisfied with life' and 'having better self-understanding'. They further reflected on 'finding relationships more meaningful' and 'respecting myself and others more'. One student described the impact of having identified her strengths as follows:

What I realized was the obvious, that the areas and activities in my life that make me feel alive, that I like, and that I focus on are my strengths. It should then be obvious that in order for me to be more alive and live my life well, I should indulge in them!

(Respondent)

This remark illustrates Peterson and Seligman's (2004) contention that strengths are characterised by a yearning to use them as well as by a sense of invigoration and ownership. One student remarked how his strength of optimism had previously been seen as a drawback:

Because of the pathology orientated model that has dominated our profession I used to conceptualize my ability to plan ahead as being obsessive rather than to appreciate my future mindedness.

(Respondent)

He continued to ascribe his academic successes directly to his positive expectation of the future and felt empowered by having identified this as a psychological strength. It therefore seems that the identification of personal psychological strengths not only made the students aware of psychological strengths existing in general but also affirmed the value of utilising and valuing their own strengths. Strümpfer (1999) stated that psychologists need to be sensitive to factors that could enhance resilience. By starting with identifying these factors in students themselves, it could therefore be easier to increase the awareness of psychologists of psychofortological factors in their clients.

Most training programmes have some focus on facilitating students' understanding of their inner dynamics and unconscious processes (Truell, 2001) that could impact upon their definition of self (Kottler \& Swartz, 2004; Mahoney, 2002). While it has been noted that student psychologists could question their own competencies (Truell, 2001), an additional focus on identifying psychological strengths could contribute to affirming positive aspects of this self-definition and thereby enhancing the psychological well-being of trainee psychologists.

\section{DISCUSSION}

The aim of this study was to explore the impact of introducing positive psychology in the professional training of psychologists. For the participants in this study, the impact was enriching and valuable on both a personal and a professional level. However, the pathogenic bias in undergraduate education did result in initial apprehension for some students, while others' original interests in the more positive aspects of human functioning had seemingly been neglected in the early years of their encounter with psychology. On a personal level, the participants experienced positive emotions and an increased sense of selfunderstanding and well-being. On a professional level, they experienced a sense of increased self-efficacy in implementing psychotherapy. Some of the participants also noted that positive psychology could provide an avenue to work with the unique challenges of South African society, as described through their experiences in implementing psychotherapy in diverse contexts.

Following on these findings, some recommendations regarding education and training in psychology in South Africa can be presented.

\section{Recommendations}

Firstly, the pathogenic bias in undergraduate education should be balanced by complementing it with some exposure to positive psychology. This could facilitate a more balanced view of psychotherapeutic interventions and professional psychology in postgraduate training.

Secondly, explicitly implementing a positive psychology stance in the basic training of psychologists should be considered. Specifically, more emphasis could be placed on the development of a balanced self-awareness that includes identification of deficits and strengths. Such an approach could enhance the development of the professional self of trainee psychologists by focusing on their unique psychological strengths. These strengths could be fruitfully applied within the therapeutic context when trainees are aware of and utilise their own strengths, while also being cognisant of identifying strengths in their clients. Another avenue of including positive psychology could be to train students in positive psychology interventions, as this could enhance the experience of self-efficacy in students, while simultaneously facilitating the psychological well-being of clients.

Thirdly, including a positive psychology approach could potentially prevent burnout and stress by making students more aware of the importance of psychological well-being in their own lives.

Fourthly, a positive psychology perspective seems relevant to working within the South African context. Through identifying, facilitating and working with psychological strengths, such as hope, gratitude, kindness and leadership, in disadvantaged communities, much could be done to enhance both individual and group well-being in our society.

Finally, integrating positive psychology in professional training could contribute to widening the scope of practice of psychologists to include capacity building and prevention. Knowledge of and training in positive psychology could thus generate psychologists with a broader skills set, one that grants them greater professional flexibility. Therefore, it could be argued that more attention should be given to incorporating positive psychology into all levels of education in psychology truly to develop the notion of a balanced psychology in South Africa.

\section{Limitations}

Despite these preliminary findings, however, there are certain limitations to the study that need consideration.

Firstly, there was a particular connection between the researcher and the students, often referred to as 'backyard research' (Creswell, 2003), which could have influenced the students to provide biased or compromised data.

And, secondly, documents were used as data, which could be incomplete in the sense that there was no opportunity to ask the participants to elaborate on their responses; this could have provided more and richer data. Neither can the findings be generalised to the experiences of students in other training programmes. It could therefore be valuable to explore the experiences of students in subsequent training programmes 
at this university and to follow these students' professional development over a few years. By including quantitative measures on these students' levels of psychological wellbeing, information in terms of the possible positive effects of including a positive psychology approach in the education and training of psychologists could be collected. Examples of hypotheses for empirical investigation include the following: Are there statistically significant differences between the therapeutic outcomes of psychologists who practise from an integrated pathogenic and positive psychology model and those who practise from the pathogenic model only? Are there significant differences in terms of psychological well-being in psychologists who practise from these two models?

By providing our students with opportunities to identify and enhance their clients' as well as their own psychological strengths and psychological well-being, we could leverage the development of a professional psychology in South Africa that could do much more for the people we are to serve.

\section{REFERENCES}

Ahmed, R., \& Pillay, A.L. (2004). Reviewing clinical psychology training in the post-apartheid period: Have we made any progress? South African Journal of Psychology, 34, 630-656.

Bacon, S.F. (2005). Positive psychology's two cultures. Review of General Psychology, 9, 181-192.

Blocher, D. (1987). The professional counsellor. London: MacMillan.

Braun, V., \& Clarke, V. (2006). Using thematic analysis in psychology. Qualitative Research in Psychology, 3, 77-101.

Cresswell, J.W. (2003). Research design: Qualitative, quantitative and mixed methods approaches. Thousand Oaks: Sage.

Diener, E. (2000). Subjective well-being: The science of happiness and proposal for a national index. American Psychologist, 55, $34-43$.

Frederickson, B.L. (2001). The role of positive emotions in positive psychology: The broaden-and-build theory of positive emotions. American Psychologist, 56, 218-226.

Frederickson, B.L. (2002). Positive emotions. In C.R. Snyder \& S.J. Lopez (Eds.), The handbook of positive psychology, (pp. 120134). New York: Oxford University Press.

Frederickson, B.L., \& Joiner, T. (2002). Positive emotions trigger upward spirals toward emotional well-being. Psychological Science, 13, 172-175.

Halewood, A., \& Tribe, R. (2003). What is the prevalence of narcissistic injury among trainee counselling psychologists? Psychology and Psychotherapy: Theory, Research and Practice, $76,87-102$

Holloway, I., \& Todres, L. (2003). The status of method: Flexibility, consistency and coherence. Qualitative Research $3,345-357$.

Howard, F. (2008). Managing stress or enhancing well-being? Positive psychology's contributions to clinical supervision. Australian Psychologist, 43, 105-113.

Ingram, R.E. (2005). Clinical training for the next millennium. Journal of Clinical Psychology, 61, 1155-1158.

Jordaan, I., Spangenberg, J.J., Watson, M.B., \& Fouchè, P. (2007). Emotional stress and coping strategies in South African clinical and counselling psychologists. South African Journal of Psychology, 37, 835-855.

Joseph, S., \& Linley, P.A. (2006). Positive therapy: A meta-theory for positive psychological practice. London: Routledge.

Keyes, C.L.M. (2007). Promoting and protecting mental health as flourishing: A complementary strategy for improving national mental health. American Psychologist, 6, 95-108.

Kottler, A., \& Swartz, S. (2004). Rites of passage: Identity and the training of clinical psychologists in the current South African context. South African Journal of Clinical Psychology, 34, 55-71.

Krefting, L. (1991). Rigor in qualitative research: The assessment of trustworthiness. The American Journal of Occupational Therapy, 45, 214-222.

Linley, P.A. (2006). Counseling psychology's positive psychological agenda: A model for integration and inspiration. The Counseling Psychologist, 34, 313-324.
Linley, P.A., Joseph, S., Harrington, S., \& Wood, A.M. (2006). Positive psychology: Past, present and (possible) future. The Journal of Positive Psychology, 1, 3-16.

Lopez, S.J., Magyar-Moe, J.L., Petersen, S.E., Ryder, J.A., Krieshok, T.S., O'Byrne, K.K., et. al. (2006). Counselling psychology's focus on positive aspects of human functioning. The Counseling Psychologist, 34, 205-230.

Lopez, S.J., Snyder, C.R., \& Rasmussen, H.N. (2003). Striking a vital balance: Developing a complementary focus on human weakness and strength through positive psychological assessment. In S.J. Lopez \& C.R. Snyder (Eds.) Positive psychological assessment: A handbook of models and measures, (pp. 3-20). Washington: American Psychological Association.

Mahoney, M.J. (2000). Training future therapists. In C.R. Snyder \& R.E. Ingram (Eds.), Handbook of psychological change: Psychotherapy processes and practices for the 21st century, (pp. 727-735). New York: Wiley.

Mollen, D., Ethington, L., \& Ridley, C.R. (2006). Positive psychology: Considerations and implication for counselling psychology. The Counseling Psychologist, 34, 304-312.

Peterson, C., \& Seligman, M.E.P. (2004). Character strengths and virtues: A handbook and classification. Washington: American Psychological Association.

Peterson, C., Park, N., \& Seligman, M.E.P. (2005). Assessment of character strengths. In G.P. Koocher, J.C. Norcross \& S.S Hill, III (Eds.), Psychologists' desk reference, (pp. 93-98). New York: Oxford University Press.

Peterson, C., Park, N., \& Sweeney, P.J. (2008). Group well-being Morale from a positive psychology perspective. Applied Psychology: An International Review, 57, 19-36.

Rashid, T. (2009). Positive interventions in clinical practice. Journal of Clinical Psychology, 65, 461-466.

Seligman, M.E.P., \& Csikszentmihalyi, M. (2000). Positive psychology: An introduction. American Psychologist, 55, 5-14.

Seligman, M.E.P., Steen, T.A., Park, N., \& Peterson, C. (2005). Positive psychology progress: Empirical validation of interventions. American Psychologist, 60, 410-421.

Smith, E. (2006). The strengths-based counseling model. The Counseling Psychologist, 34, 13-79.

Snyder, C.R., \& Elliot, T.R. (2005). Twenty-first century graduate education in clinical psychology: A four-level matrix model. Journal of Clinical Psychology, 61, 1033-1954.

Snyder, C.R., \& McCullough, M. (2000). A positive psychology field of dreams: 'If you build it, they will come ....' Journal of Social and Clinical Psychology, 19, 151-160.

Snyder, C.R., Ritchel, R.A., Rand K.L., \& Berg, C.J. (2006) Balancing psychological assessments: Including hope and strengths in client reports. Journal of Clinical Psychology, 62, 33-46.

Strümpfer, D.J.W. (1979). A general hospital patient is not a NUT. South African Journal of Psychology, 9, 67-74. Retrieved July 17, 2009 from EBSCO database.

Strümpfer, D.J.W. (1995). The origins of health and strengths: From 'salutogenesis' to 'fortigenesis'. South African Journal of Psychology, 25, 81-89.

Strümpfer, D.J.W. (1999). Psychosocial resilience in adults. Studia Psychologica, 41, 89-104.

Strümpfer, D.J.W. (2005). Standing on the shoulders of giants: Notes on early positive psychology. South African Journal of Psychology, 35, 21-44.

Tilson, C. (2006). Positive psychology and psychotherapists' beliefs. Unpublished doctoral thesis, Wright Institute Graduate School of Psychology, Berkeley.

Truell, R. (2001). The stresses of learning counselling: Six recent graduates comment on their personal experiences of learning counselling and what can be done to reduce associated harm. Counselling Psychology Quarterly, 1, 67-89.

Viviers, R., \& Coetzee, S. (2007). South African universities, research and positive psychology. South African Journal for Higher Education, 2, 764-780.

Wissing, M.P., \& Van Eeden, C. (2002). Empirical clarification on the nature of psychological well-being. South African Journal of Psychology, 32, 32-44. 